\title{
Adult Astrocytic Tumor
}

National Cancer Institute

\section{Source}

National Cancer Institute. Adult Astrocytic Tumor. NCI Thesaurus. Code C7049.

An astrocytic tumor occurring during adulthood. Representative examples include diffuse astrocytoma, anaplastic astrocytoma, and glioblastoma. 